\title{
A pesquisa em Artes Visuais nas revistas acadêmicas
}

\begin{abstract}
Alexandre Sá Barretto da Paixão', Mario Grisolli", Rayssa Veríssimo Correall' e Rudolf Kurz ${ }^{\mathrm{IV}}$
Resumo: Este artigo busca analisar, de maneira sucinta, parte da produção das revistas acadêmicas de Artes Visuais no território brasileiro. Diante da amplitude do tema, optou-se, neste primeiro momento, pelo estabelecimento de um pequeno panorama dos periódicos Al da área, visando estabelecer relações entre as produções e seus processos avaliativos, bem como suas conexões com as estruturas econômicas, culturais, geográficas e respectivos apoios institucionais. Para realizar esta pesquisa, utilizou-se uma metodologia de cunho quantitativo e qualitativo aliada à pesquisa bibliográfica.
\end{abstract}

Palavras-chaves: Periódicos acadêmicos. Artes Visuais. Qualis. Indexadores.

\section{Research in Visual Arts in academic journals}

Abstract: This article seeks to analyze, briefly, part of the production of Visual Arts academic journals in Brazil. Given the breadth of the theme, it was decided, at this first moment, to establish a small overview of A1 journals in the area, in order to establish relationships between the productions and their evaluation processes, as well as their connections with the economic, cultural and geographical structures and their respective institutional support. A quantitative and qualitative methodology allied to bibliographical research was used.

Keywords: Academic journals. Visual Arts. Qualis. Indexers.

I Artista-pesquisador, curador, crítico de arte e psicanalista. Pós-doutorando em História pelo PPGH- UFF. Procientista/ UERJ com o projeto As revistas acadêmicas de Artes Visuais. Atual diretor do Instituto de Artes e professor do PPGARTES/ UERJ. Sócio da Associação Brasileira de Críticos de Arte. Membro da ANPAP - Comitê de Poéticas Artísticas. Membro da Associação Nacional de História (ANPUH). Docente da Universidade do Estado do Rio de Janeiro - Rua São Francisco Xavier, 524 - Maracanã, Rio de Janeiro - RJ, 20550-013. E-mail: alexandresabarretto@gmail.com. ORCID: https://orcid. org/0000-0002-7846-5145. Lattes iD: lattes.cnpq.br/0137944963846547. Niterói, RJ, Brasil.

II Artista, fotógrafo e pesquisador. Graduando em Artes Visuais pela Universidade do Estado do Rio de Janeiro. Bolsista de iniciação científica pelo CNPQ no projeto A pesquisa em Artes Visuais nas revistas acadêmicas, sob orientação de Alexandre Sá. Editor executivo da revista Concinnitas, do Instituto de Artes da UERJ. Integra o grupo de pesquisa A Arte Contemporânea e o Estádio do Espelho, certificado pelo CNPQ. Discente da Universidade do Estado do Rio de Janeiro - Rua São Francisco Xavier, 524 - Maracanã, Rio de Janeiro - RJ, 20550-013. E-mail: mariogrisolli@gmail.com ORCID: https://orcid.org/0000-0002-4154-2848 Lattes iD: http://lattes.cnpq.br/6212338728777030 Rio de Janeiro, RJ, Brasil.

III Graduanda em Artes Visuais na Universidade do Estado do Rio de Janeiro (UERJ), colaboradora da revista Concinnitas e bolsista de extensão do projeto A crítica, coordenado por Alexandre Sá, quem a orienta no projeto de iniciação científica A pesquisa em Artes Visuais nas revistas acadêmicas, do qual é pesquisadora voluntária. Discente da Universidade do Estado do Rio de Janeiro - Rua São Francisco Xavier, 524 - Maracanã, Rio de Janeiro - RJ, 20550013. E-mail: rayssaverissimocorrea@gmail.com. ORCID: https://orcid.org/0000-0001-8148-0840. Lattes iD: http://lattes.cnpq.br/4242348471753455. São Pedro da Aldeia, RJ, Brasil.

IV Artista visual, pesquisador e curador. Graduando em Artes Visuais pela UERJ e graduado em Economia pela mesma instituição. Faz parte da equipe editorial da Revista Concinnitas. Integra o grupo de pesquisa "A pesquisa em Artes Visuais nas revistas acadêmicas" e o projeto de extensão "A Crítica", ambos coordenados por Alexandre Sá, sendo este último também coordenado por Renata Gesomino. Discente da Universidade do Estado do Rio de Janeiro - Rua São Francisco Xavier, 524 - Maracanã, Rio de Janeiro - RJ, 20550-013. E-mail: kurzjr@gmail.com. ORCID: https:// orcid.org/0000-0002-3235-4933. Lattes iD: http://lattes.cnpq.br/6717603488916587. Rio de Janeiro, RJ, Brasil. 
Este artigo é o primeiro movimento de um projeto de pesquisa que reúne alunos bolsistas ${ }^{1}$ de iniciação científica, estágio interno complementar e extensão sobre as revistas acadêmicas de Artes Visuais e suas possíveis relações com a tecnologia, tentando problematizar sua recepção dentro do universo virtual, através do uso majoritário da plataforma OJS, bem como dos desafios que surgem na utilização de imagens, vídeos e outras proposições visuais, fundamentais para a área, não inteiramente contempladas por um processo pouco ampliado de construção científica. Contudo, se inicialmente a preocupação com a prática visual em revistas acadêmicas foi o elemento estruturante de tal projeto, é fundamental explicitar que compreendeu-se a necessidade urgente de uma investigação mais apurada de tais publicações no país, através de um mapeamento inicial de modo a compreender qualitativamente quais as particularidades desses veículos. Então é possível afirmar que, embora a preocupação inicial tenha sido especificamente tecnológica, foi necessário retroceder um pouco em nossos objetivos para que pudéssemos analisar de maneira mais verticalizada parte do processo editorial que as erige e de qual maneira elementos outros, não estritamente acadêmicos, podem vir a ser definidores de uma considerável qualidade, capaz de ser comprovada, de acordo com as métricas governamentais, através do Qualis Periódicos.

Sendo assim, destaca-se como objetivo deste artigo, a estruturação de um micropanorama atual do cenário brasileiro da pesquisa em Artes, através da ótica de parte de seus periódicos, com base nos critérios avaliativos da CAPES, tendo consciência do risco de tal mapeamento já que esses mesmos balizadores poderão em breve ser modificados ${ }^{2}$. De todo modo, é importante explicitar que originalmente o Qualis Periódicos visava avaliar parte da produção científica dos Programas de Pós-Graduação existentes, mas ao longo do seu processo, o mesmo serviu para avaliações pessoais, profissionais e em alguns casos, como condição determinante para o magistério, concessão de títulos e bolsas de pesquisa e para a manutenção de bolsas de alunos de mestrado e doutorado. Nos períodos anteriores, disponíveis na Plataforma Sucupira, os periódicos avaliados são classificados como A1, A2, B1, B2, B3, B4, B5 e C. No estrato A1 estão os periódicos melhor qualificados, segundo um fator de impacto quantificado através de citações.

1 Mario Grisolli (bolsista de iniciação científica CNPq/UERJ), Rayssa Veríssimo (bolsista de extensão - UERJ) e Rudolf Kurz (bolsista de estágio interno complementar - UERJ)

2 Em 2019, ocorreu o Seminário de Meio Termo do quadriênio 2017-2020, organizado pela CAPES, onde foram testadas novas referências para o Qualis. 
Como metodologia de pesquisa, buscou-se, primeiramente, inventariar as publicações de excelência na área de Artes, destacadas como A1 na Plataforma Sucupira ${ }^{3}$ no período mais recente disponível, o quadriênio 2013 - 2016. Nosso estudo observa a nacionalidade, a localização regional e as disciplinas de concentração dos periódicos listados, subdivididas em temas nomeados Música, História da Arte, Artes Cênicas e Artes Visuais ${ }^{4}$. Em um segundo momento, apresentou-se um estudo de caso específico de alguns desses periódicos, observando alguns dos critérios avaliativos da CAPES e singularidades notáveis. Por fim, foram observadas práticas editoriais e suas possíveis relações com critérios avaliativos e com os indexadores.

Embora a CAPES faça menção ao quadriênio 2017 - 2020, este período ainda não está disponível para consulta. Portanto, no primeiro movimento de mapeamento das revistas acadêmicas brasileiras em Artes Visuais, utilizou-se como referência as informações do período de avaliação mais recente acessível no sistema. Dado esse recorte (quadriênio 2013 - 2016), as informações coletadas podem apresentar discrepâncias com o momento atual, fato que não tira a utilidade dos dados obtidos para a análise do cenário brasileiro da pesquisa científica em Artes.

A coleta preliminar de dados das revistas A1 foi o ponto de partida para a construção do panorama construído com o cruzamento de informações obtidas nos sites de cada periódico e/ou de suas plataformas. Essa busca apresenta uma contradição imediata: apesar da Plataforma Sucupira informar que há 26 registros, apenas 22 podem ser visualizados. Essa análise permitiu também identificar uma duplicidade que ocorre devido à transição de revistas do meio impresso para o meio digital. Com a mudança dos meios de publicação, algumas revistas permaneceram na plataforma com dois ISSNs diferentes (Número Internacional Normalizado para Publicações Seriadas), levando à repetição de alguns dados. Desta forma, descartando as repetições e os registros não demonstrados, estão listadas dezoito (18) publicações na área de Artes, classificadas como A1.

3 Base de referência para o Sistema Nacional de Pós-Graduação (SNPG).

4 A Tabela de Áreas do Conhecimento da CAPES, disponível em https://www.gov.br/capes/ $\mathrm{pt-br/acesso-a-informacao/acoes-e-programas/avaliacao/instrumentos/documentos-de-}$ -apoio-1/tabela-de-areas-de-conhecimento-avaliacao, divide a área de Artes em diversas subáreas, mas não disponibiliza a classificação dos periódicos por subáreas e especialidades em sua plataforma. Optamos então por subdividir a área em temas de acordo com a autodeclaração das próprias revistas. 
A organização dos dados tornou possível visualizar e compreender a distribuição geográfica desses periódicos. Do total de dezoito (18) periódicos classificados como A1 no quadriênio 2013 - 2016, nove (09) são brasileiros e nove (09) de outras nacionalidades, conforme apresentado no Gráfico 1. De acordo com a coordenadora de Artes na CAPES, Vera Beatriz Siqueira (2020, 40'37"), a presença de periódicos estrangeiros na lista é fruto da publicação de autores brasileiros nesses periódicos, levando à inclusão dos mesmos na lista de classificação publicada na Plataforma Sucupira. De modo contrário à prática internacional, todos os periódicos nacionais listados adotam a política de Acesso Aberto 5 .

Ao observarmos a área de Artes em subdivisões temáticas de atuação, os dados apontam outro desequilíbrio: as Artes Visuais foram representadas por apenas uma (01) publicação: a revista ARS6. Conforme apresentado no Gráfico 2, pode-se verificar maior concentração nas subdivisões Música, História da Arte e Artes Cênicas.

\section{PERIÓDICOS A1 POR PAÍS}

Gráfico 1

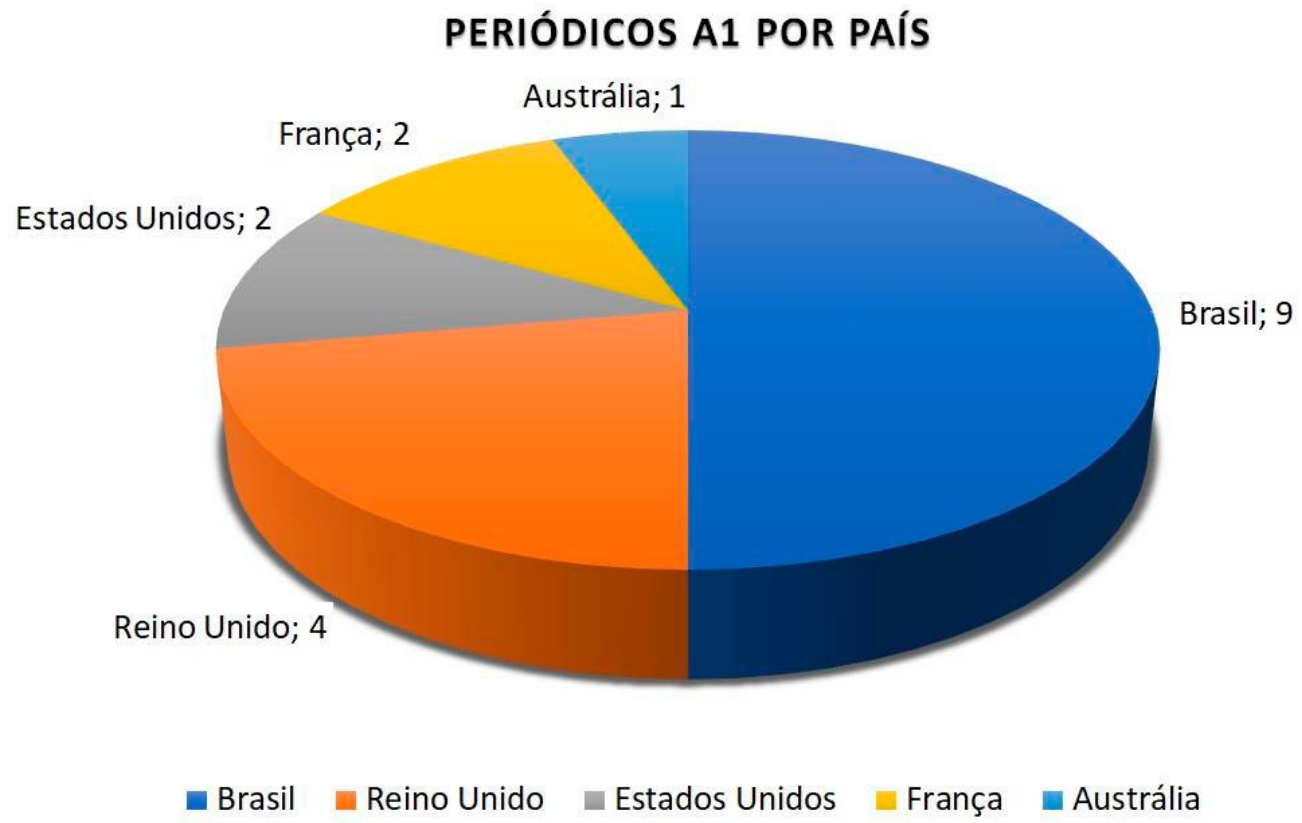

5 A política de Acesso Aberto promove acesso gratuito ao resultado das pesquisas científicas veiculado nos periódicos.

6 A revista ARS é uma publicação do Programa de Pós-Graduação em Artes Visuais da Escola de Comunicações e Artes da Universidade de São Paulo (USP). 
Gráfico 2

Periódicos por subdivisão temática (fonte: Plataforma Sucupira, CAPES, 2021)

\section{PERIÓDICOS POR SUBDIVISÃO TEMÁTICA}

$\square$ Música $\square$ História da Arte $\square$ Artes Cênicas $\square$ Artes Visuais

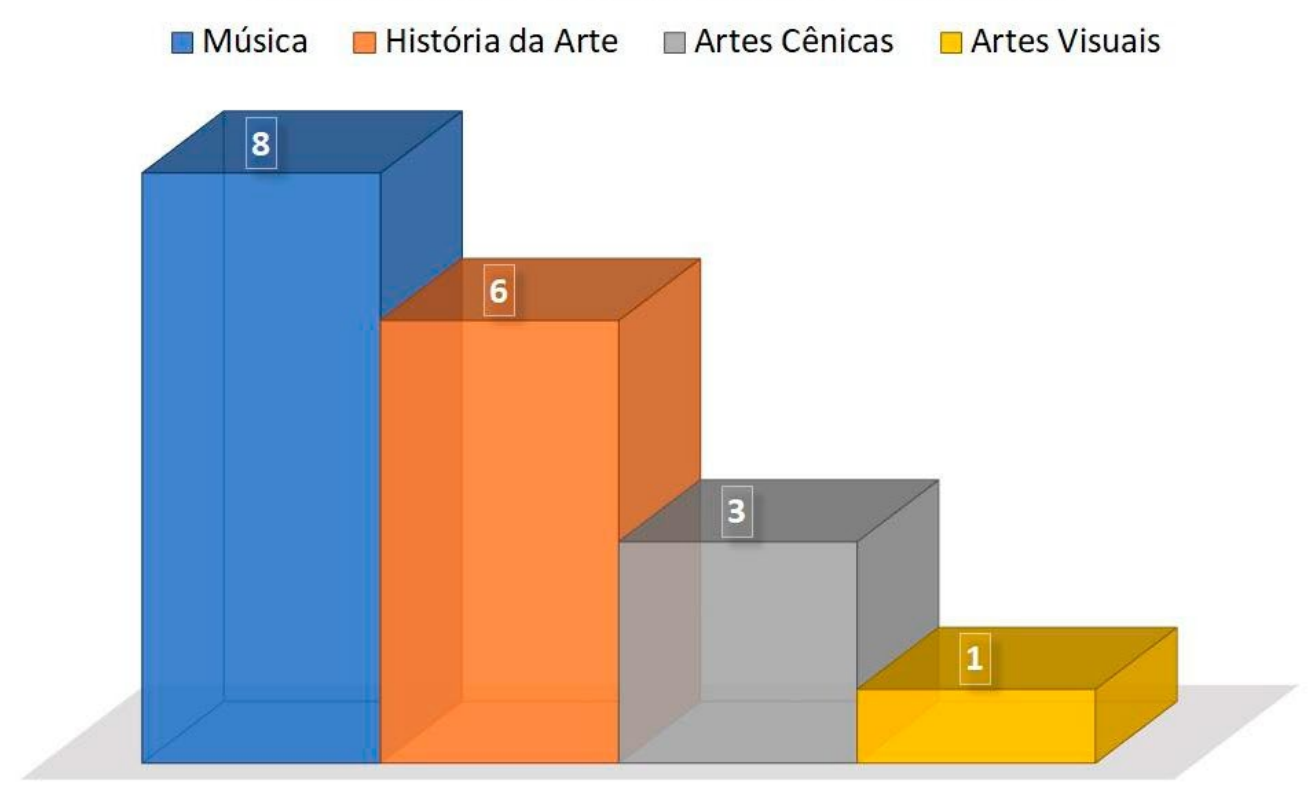

Desconsiderando as publicações internacionais, situadas em um contexto econômico e educacional diferente do brasileiro, a análise dos dados revela a predominância das regiões Sudeste e Sul, sendo estas duas as únicas regiões do Brasil representadas por periódicos qualificados como A1 pela CAPES no quadriênio 2013 - 2016. Além disso, o Estado de São Paulo tem uma quantidade superior de revistas em comparação com os demais Estados citados nos dados.

\section{PERIÓDICOS BRASILEIROS POR REGIÃO}

Gráfico 3 Periódicos Brasileiros por Região (fonte: Plataforma Sucupira, CAPES, 2021)

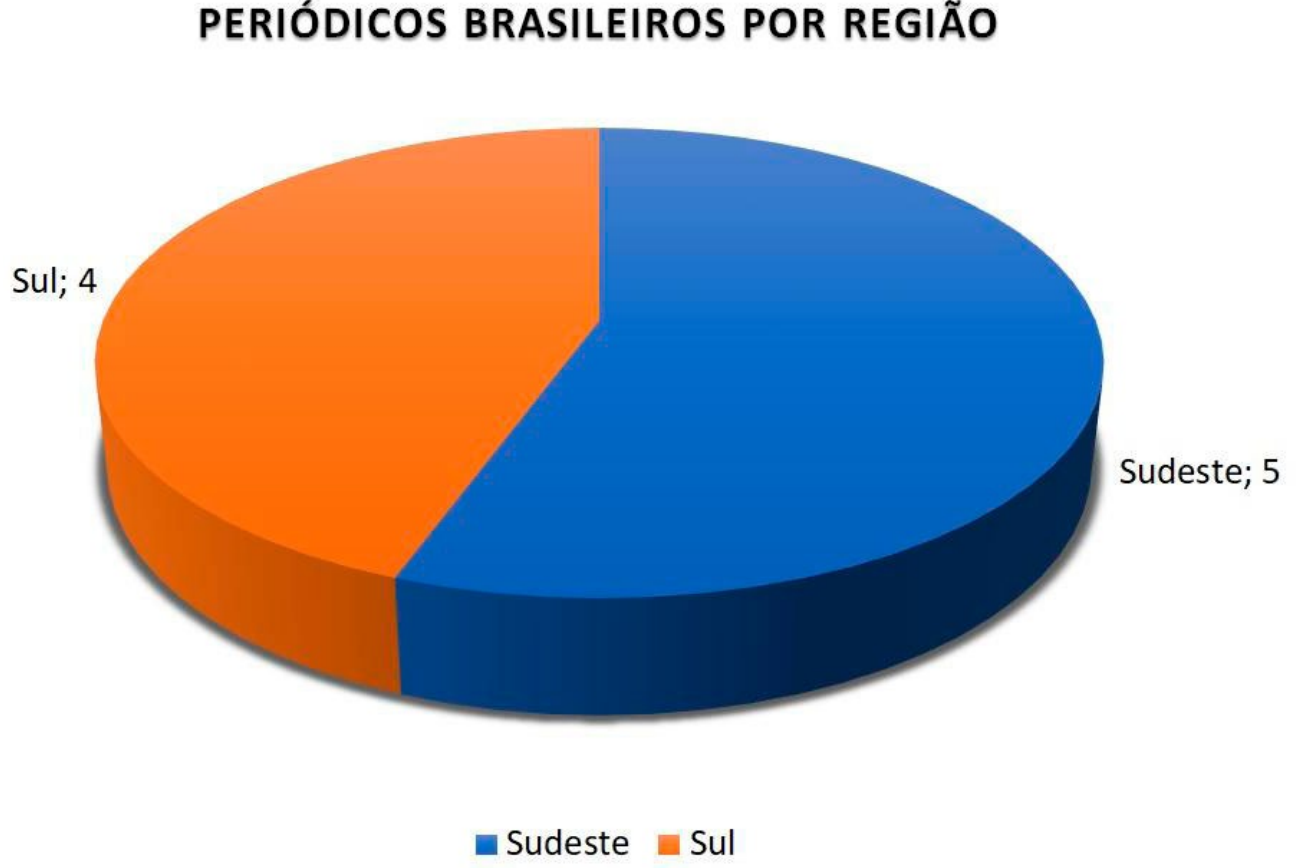




\section{PERIÓDICOS DA REGIÃO SUDESTE POR ESTADO}

Gráfico 4 Periódicos da Região Sudeste por Estado (fonte: Plataforma Sucupira, CAPES, 2021)

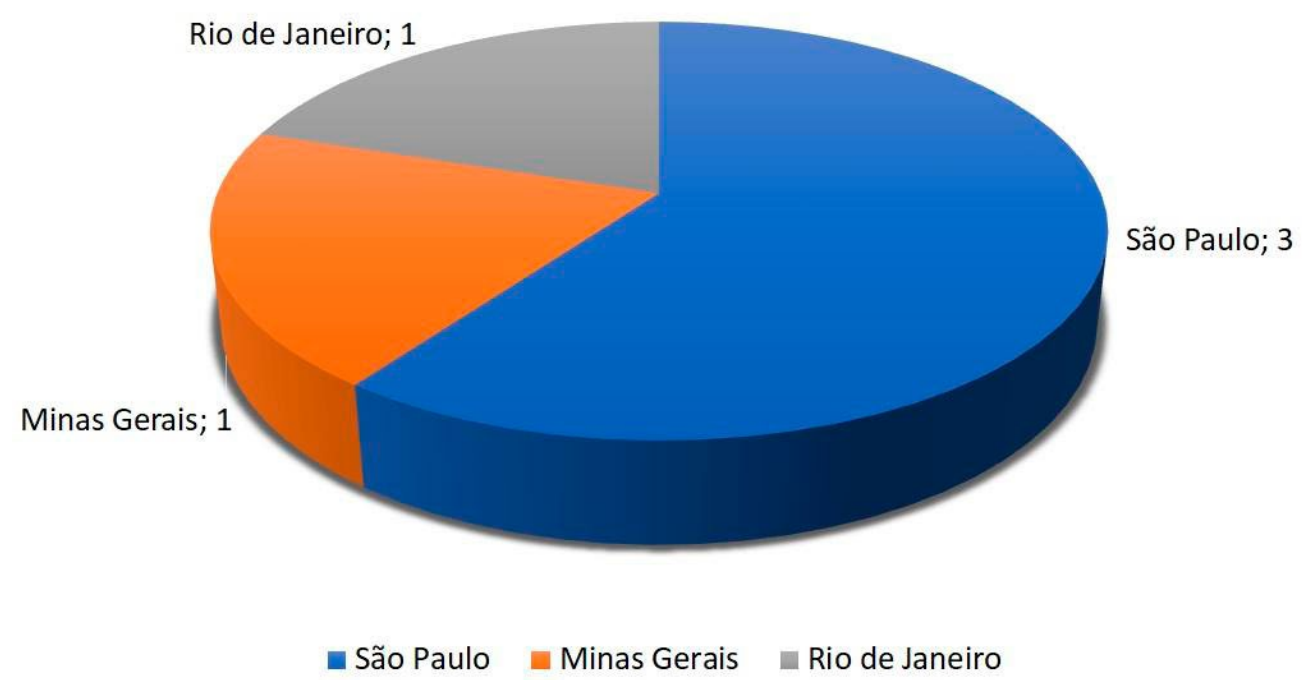

\section{Panorama da avaliação Qualis Periódico}

O resultado das observações obtidas através dos dados do quadriênio 2013 - 2016 foi posteriormente comparado aos dados do triênio 2010 - 2012. A análise mostra que a quantidade de periódicos que têm Artes como área mãe, qualificados como A1 no quadriênio 2013 - 2016, diminuiu 26\% em relação ao triênio anterior. Os dados são consistentes ao mostrar um deslocamento da categoria $A 1$ para a categoria $A 2$, em um fluxo descendente, indicando, apesar dessa redução, o ingresso de quinze (15) novos periódicos na listagem total, o que representa um aumento de $18 \%$ do número de periódicos A1 e A2 somados de um período para o outro.

\begin{tabular}{|c|c|c|}
\hline $\begin{array}{c}\text { Classificação / } \\
\text { Periodo }\end{array}$ & $\begin{array}{c}\text { Triênio } \\
\text { 2010-2012 }\end{array}$ & $\begin{array}{c}\text { Quadriênio } \\
\text { 2013-2016 }\end{array}$ \\
\hline A1 & 35 & 26 \\
\hline A2 & 49 & 73 \\
\hline Total de periódicos & 84 & 99 \\
\hline
\end{tabular}

7 O Estado do Espírito Santo não possui publicações A1 nos dados disponibilizados pela CAPES. 
Os critérios para o próximo quadriênio (2017 - 2020) ainda são aguardados e, até o momento da finalização deste artigo, ainda não haviam sido oficialmente definidos. No centro desse debate, em 18 de julho de 2019, foi divulgado o Relatório do Qualis Periódicos, onde a Coordenadoria de Artes da CAPES manifesta preocupação em equilibrar uma ausência ou insuficiência de indicadores bibliométricos objetivos, quando fez testes para o novo Qualis Referência, tendo como base os anos 2017 e 2018. Para compensar o baixo índice de citações da área de Artes nas principais bases indexadoras (Web of Science e Scopus), o modelo utilizado na testagem faz uma combinação de dados com percentuais obtidos através do índice $h$ do Google Scholar. Além disso, com o intuito de incentivar a profissionalização e a internacionalização da produção científica veiculada nos periódicos acadêmicos, foram sugeridos, no documento, os seguintes parâmetros normativos:

- Presença de ISSN e política editorial claramente definida;

- Divulgação on-line das chamadas (fluxos contínuos, números temáticos etc.) e procedimentos para receber artigos;

- Descrição do sistema de controle de qualidade: política de detecção de plágio, avaliação às cegas por pares, obediência a normas técnicas editoriais (ABNT ou equivalente), formas de acesso;

- Dados da instituição de publicação, do editor responsável e/ou Comissão Editorial e do Conselho Editorial com afiliação institucional diversificada de seus membros;

- Periodicidade regular e atualizada (seriada, contínua, ahead of print etc.);

- Identificação dos autores, com titulação, afiliação institucional, e-mail, identificadores persistentes de autores (ORCID ou similares);

- Resumo em Língua Portuguesa e em, pelo menos, uma língua estrangeira, seguido de palavras-chave;

- Identificação dos artigos por DOI;

- Inclusão da data de recebimento e de aprovação de cada artigo;

- Disponibilização de Acesso Aberto;

- Presença em bases indexadoras e buscadores;

Fonte: Relatório do Qualis Periódicos, CAPES, 2019 


\section{Estudos de caso específicos}

Tendo em vista o panorama levantado que, dentre os nove (09) periódicos brasileiros classificados como A1 na área de Artes no quadriênio 2013 - 2016, apresenta apenas uma (01) publicação que se dedica especificamente à subdivisão temática Artes Visuais, optou-se por observá-la de maneira mais próxima, juntamente com uma revista de longa trajetória, fundada em 1922, que, embora seja comumente apresentada como pertencente a outras áreas ${ }^{8}$, foi também classificada, na Plataforma Sucupira, como A1 no quadriênio 2013 - 2016, na área de Artes.

Ambas as revistas são produzidas na Universidade do Estado de São Paulo (USP), primeira instituição a criar um Programa de Pós-Graduação em Artes no Brasil, na década de 1970. A Ars é uma jovem revista acadêmica que começou a circular em 2003 e, em 2017, passou a ser vinculada ao Programa de Pós-Graduação de Escola de Comunicação e Artes (ECA-USP), enquanto a Anais do Museu Paulista: História e Cultura Material tem quase cem anos e apresenta vínculo com o Museu Paulista, também uma unidade da USP.

De acordo com informações do Portal de Revistas da USP, os dois periódicos observados não possuem Editor-chefe em seus corpos editoriais. A Ars possui quatro (04) editores (um externo à USP); trinta e um (31) membros na comissão editorial [um in memoriam, Walter Zanini, dez (10) internacionais, nove (09) internos e onze (11) externos à USP]. Além disso, a equipe possui um (01) profissional para cada uma das seguintes áreas, sem repetição de cargo: comunicação institucional; projeto gráfico; produção e assistência editorial.

Já a Anais do Museu Paulista: História e Cultura Material possui dois (02) editores vinculados ao Museu Paulista da Universidade de São Paulo; trinta e um (31) membros no conselho consultivo [cinco (05) internacionais, seis (06) internos e vinte (20) externos à USP]. Sua equipe de produção editorial conta com cinco (05) profissionais, um (01) com cargo repetido, e duas (02) empresas prestadoras de serviço (Foco Digital Serviços Editoriais Ltda. E Tikinet Edição Ltda.). Entretanto, há uma disparidade com o

8 Apresentada nesse estrato em: Periódicos CAPES (Ciências Humanas: História, Sociologia); Scielo (Ciências Sociais Aplicadas, Ciências Humanas); Redalyc (História); DOAJ (História da América: América Latina, América espanhola) e Latindex (História, Cultura). 
site da SCIELO, que informa que a equipe de produção editorial conta com seis (06) pessoas, uma com cargo repetido, e três (03) empresas (Foco Digital Serviços Editoriais Ltda, Tikinet Edição Ltda EPP e MM Coutinho Auditoria Ltda. ME).

Enquanto a Ars recebe artigos em fluxo contínuo, realiza eventuais chamadas abertas e publicou semestralmente até 2017, quando passou a ser uma publicação quadrimestral; a Anais do Museu Paulista também recebe artigos em fluxo contínuo mas, a partir de 2018 passou a funcionar no sistema de publicação contínua, compilando a produção em um volume único anual.

Compartilhando a infraestrutura institucional da USP, esses periódicos cumprem grande parte dos critérios de excelência que servem como referência para a avaliação sugerida no Relatório do Qualis Periódicos supracitado. São publicados através da plataforma OJS, adotam avaliação duplo-cega por pares de pareceristas ad hoc e a política de Acesso Aberto, além disso, beneficiam-se do Programa de Apoio às Publicações Científicas Periódicas da USP e utilizam as ferramentas antiplágio disponíveis à comunidade científica dessa Universidade.

Disponibilizadas gratuitamente no Portal de Revistas da USP, ambas as revistas contam com importantes indexadores, tendo em comum SciELO, Latindex e DOAJ. Além disso, a Anais do Museu Paulista é indexada também pela base REDALyC. É importante notar que a SCIELO é um dos mais rigorosos sistemas de indexação, juntamente com Web of Science e Scopus, estes últimos ainda não alcançados por nenhum periódico da área de Artes, no Brasil. A presença dos periódicos em bases indexadoras é um dado relevante, devido ao peso da citação na classificação de Periódicos Acadêmicos. Influenciada pela carência de citações da área de Artes, a CAPES sugere, no relatório de 2019, a imputação de dados extraídos através do índice $h$ do Google, visando minimizar distorções e proporcionar um meIhor mapeamento da produção científica nacional na área.

As duas revistas recebem aporte financeiro do Programa de Apoio às Publicações Periódicas da Agência USP de Gestão da Informação Acadêmica (AGUIA). Este programa de apoio institucional publica editais que visam apoiar projetos de editores da USP que tenham por objetivo o aperfeiçoamento de seus periódicos nos seguintes aspectos: aumento do fator de impacto, internacionalização e produção editorial (incluindo diagramação, tradução, revisão gramatical e, excepcionalmente, impressão). 
O edital 2021, divulgado no Portal de Revistas da USP, disponibiliza um total de $\mathrm{R} \$ 1.600 .000,00$ (US $\$ 312.762,06$ ) 9 a serem distribuídos de acordo com critérios de classificação do periódico. Esses critérios separam os concorrentes em três (03) faixas. A saber, os periódicos que apenas atendem às exigências do edital concorrem a $\mathrm{R} \$ 10.000,00$ (US\$1.954,76); aqueles que, além disso, possuem indexação no SciELO ou em indexador internacional de referência para a área de conhecimento passam a concorrer por $\mathrm{R} \$ 30.000,00$ (US\$5.864,29); e aqueles que somam a tudo indexação na base Web of Science e/ou base Scopus podem receber $\mathrm{R} \$ 60.000,00$ (US\$11.728,58). No portal, são disponibilizados links para as versões anteriores do edital, desde 2013. Até 2018, o edital não divulgou o total de recursos oferecidos. No lugar disso, solicitava um quadro demonstrativo com todas as receitas, respectivas fontes, e despesas efetuadas no ano anterior, e detalhamento de cada item. Não há link para o edital de 2019, e o de 2020 não divulga o total de recursos oferecidos, mas distribui a verba em 4 faixas, de acordo com a classificação por indexação. Neste ano, foram oferecidos $\mathrm{R} \$ 14.000,00$ (US $\$ 2.736,67$ ) para periódicos que atendessem aos requisitos do edital; $\mathrm{R} \$ 40.000,00$ (US $\$ 7.819,05$ ) para periódicos com classificação Qualis B1 ou superior no quadriênio 2013-2016, em sua área de conhecimento principal; $\mathrm{R} \$ 70.000,00$ (US $\$ 13.683,34$ ) para periódicos que, além disso, estivessem indexados no SCIELO ou em indexador internacional de referência para a área; e R120.000,00 (US $\$ 23.457,15$ ) para periódicos que, além de tudo, fossem indexados na base Web of Science e/ou Scopus. Pode-se notar que há um decréscimo significativo nos valores oferecidos pelo edital de fomento às revistas científicas da USP de 2020 a 2021.

\section{Conclusões}

Durante o processo de pesquisa, encontrou-se dificuldade em reconhecer as subáreas temáticas das revistas de Artes e em localizar dados oficiais que esclarecessem a contradição da Plataforma Sucupira que não explica quatro (04) registros de periódicos listados como A1 no quadriênio 2013 - 2016. Outro obstáculo foi localizar os critérios de avaliação das revistas acadêmicas de Artes Visuais nos períodos apurados (triênio 2010 - 2012 e quadriênio 2013 - 2016), apesar de existirem esforços manifestados pela CAPES para dar mais transparência ao processo. 
Os dados analisados, entretanto, ajudaram na compreensão da prática editorial em Artes, área jovem que enfrenta ambiguidades em relação à prática científica e que, segundo o relatório da CAPES, apresenta deficiência em profissionalização, internacionalização e citação. A correção dessa escassez parece depender de suporte institucional e econômico. Sem tal apoio, as revistas subordinam-se ao trabalho voluntário e funcionam com equipes reduzidas. Entretanto, a ARS e Anais do Museu Paulista apresentam distribuição da equipe sem repetição de cargos e um quadro que conta com prestadores de serviços especializados, facilitados pelo apoio e incentivo financeiro recebidos.

A internacionalização está relacionada à presença do periódico em uma variedade de indexadores, sendo característica da área de Artes a dificuldade de inserção nessas bases, tendo em vista a ausência de periódicos da área nas bases Web of Science e Scopus. Estas duas bases indexadoras mantêm alto grau de exigência em relação à publicação de artigos em inglês, demandando traduções para outros idiomas, em especial o inglês, tornando necessária a contratação de profissionais capacitados para desempenhar essas funções.

Nesse sentido, a falta de financiamento aparenta estar diretamente ligada à quantidade reduzida de artigos nacionais traduzidos, impactando na quantidade de citações. Apesar da área de Artes adotar amplamente o Acesso Aberto em seus periódicos acadêmicos, a dificuldade de internacionalização resulta na baixa posição da área no mapeamento nacional da produção científica. Embora a prática do Acesso Aberto seja proveitosa para a área de Artes, no sentido de dar visibilidade à produção ao difundir gratuitamente o conhecimento, a área depara-se com grave carência de aporte financeiro para a sua manutenção. A capacidade econômica parece estar ligada à discrepância regional encontrada na análise de dados, uma vez que os periódicos de excelência se concentram nas instituições com maior disponibilidade financeira, sendo São Paulo predominante na produção dos periódicos observados.

As propostas da CAPES, expressas no Relatório do Qualis Periódicos, manifestam preocupação com as questões específicas da área de Artes e buscam reduzir suas deficiências. Entretanto, outros desafios estão postos para o futuro, quando são observadas as relações entre tecnologia e a variedade de linguagens artísticas que utilizam imagens, vídeos e outras proposições visuais, fundamentais para a área. A incorporação de novas mídias pode implicar em uma negociação com os critérios avaliativos estudados, bem como com os indexadores e com a possível dificuldade de reconhecimento da área como uma construção do saber científico. Como estas ferramentas, que têm evidente afinidade com as linguagens artísticas, poderiam contribuir para a produção de conhecimento científico na área de Artes? 


\section{Referências}

ANAIS DO MUSEU PAULISTA: HISTÓRIA E CULTURA MATERIAL. [Site institucional]. Disponível em: https://www.revistas.usp.br/anaismp. Acesso em: 12 jul. 2021.

ARS. [Site institucional]. Disponível em: https://www.revistas.usp.br/ars. Acesso em: 11 abr. 2021.

BORGES, L. da C.; DA SILVA JUNIOR, P. M.; CASTRO, A. G.; VITIELLO, B. C. Acesso aberto na área de Artes: uma análise do Qualis periódicos (2010-2012) e (2013-2016). Ciência da Informação, [S. l.], v. 48, n. 3, 2020. Disponível em: http://revista.ibict.br/ciinf/article/view/4859. Acesso em: 11 ago. 2021.

CAPES. [Site institucional]. Disponível em: https://www.gov.br/capes/ pt-br. Acesso em: 17 ago. 2021.

CAPES; Relatório do Qualis Periódicos - Artes, 2019. Disponível em: https:// www.gov.br/capes/pt-br/centrais-de-conteudo/relatorio-qualis-artes-pdf. Acesso em: 17 jul.2021.

CAPES; Relatório do Seminário de Meio Termo - Artes. Brasília, 2019. Disponível em: https://www.gov.br/capes/pt-br/centrais-de-conteudo/documentos/avaliacao/REL_MEIO_TERMO_ARTES.pdf. Acesso em 17 jul. 2021.

CAPES. Tabela de Áreas de Conhecimento/Avaliação. Disponível em: https://www.gov.br/capes/pt-br/acesso-a-informacao/acoes-e-programas/avaliacao/instrumentos/documentos-de-apoio-1/tabela-de-areas-de-conhecimento-avaliacao. Acesso em: 17 ago. 2021.

PLATAFORMA SUCUPIRA. [Site institucional]. Disponível em: https://sucupira.capes.gov.br/sucupira/. Acesso em 17 jul. 2021.

PORTAL REVISTAS USP. [Site institucional]. Disponível em: https://www. revistas.usp.br/wp/sobre-o-portal/. Acesso em: 11 abr. 2021.

SCIELO. [Site institucional]. Disponível em: https://www.scielo.org/. Acesso em: 17 jul.2021.

SIQUEIRA, Vera Beatriz. Palestra proferida no seminário A pesquisa em Artes Visuais nas revistas acadêmicas, 2020. Disponível em ttps://www. youtube.com/watch?v=QOMvu52UOEs. Acesso em: 11 abr. 2021. 